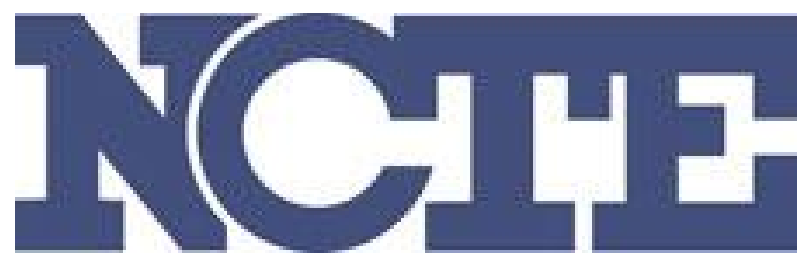

Evaluating Instruction in Writing: Approaches and Instruments Author(s): CCCC Committee on Teaching and Its Evaluation in Composition

Source: College Composition and Communication, Vol. 33, No. 2 (May, 1982), pp. 213-229 Published by: National Council of Teachers of English

Stable URL: http://www.jstor.org/stable/357630

Accessed: 29-08-2016 16:31 UTC

JSTOR is a not-for-profit service that helps scholars, researchers, and students discover, use, and build upon a wide range of content in a trusted digital archive. We use information technology and tools to increase productivity and facilitate new forms of scholarship. For more information about JSTOR, please contact support@jstor.org.

Your use of the JSTOR archive indicates your acceptance of the Terms \& Conditions of Use, available at http://about.jstor.org/terms

National Council of Teachers of English is collaborating with JSTOR to digitize, preserve and extend access to College Composition and Communication 


\title{
Evaluating Instruction in Writing: Approaches and Instruments
}

\author{
CCCC Committee on Teaching and Its Evaluation in Composition
}

Probably the one professional action that most directors of composition programs perform without dependable knowledge of what they are doing is to evaluate the instruction in writing that they supervise. Upon such evaluations we base decisions about the careers of teachers, the fate of programs, the spending of money, and the stance we take toward the public. But most of us probably have seldom, if ever, considered the premises and assumptions underlying our techniques for evaluation, or inquired about the dependability of the results we publicize.

Indeed, most of us whose responsibility it is to evaluate the teaching of writing do so with techniques and instruments developed for other kinds of teaching - teaching that is designed to impart knowledge, to encourage distinctive habits of inquiry and analysis, to develop skills, to instill attitudes and values. Such teaching typically includes giving lectures, carrying on class discussions, assigning laboratory work, and guiding practice in activities that build skills. We use such techniques and instruments for evaluation because they are repeatedly set forth in the substantial literature on evaluating teaching-and often discussed with the support of sophisticated descriptive and quantitative research. Quietly most of us assume, probably without thinking about the matter, that the teaching of writing is basically similar to these other, familiar, kinds of teaching. Or we assume that, even if our work may be different, the procedures applied in evaluating other kinds of teaching will yield valid, reliable results for us, too.

Most of us have been given no reason to doubt these assumptions, either, for if we seek research on or theoretical investigations into the evaluation of

Committee members: Lucy Grigsby, Atlanta University; Kris D. Gutierrez, University of Colorado; Maxine Hairston, University of Texas; James Kulik, University of Michigan (who contributed materials for the Committee's study but did not participate in the writing of these documents); Elisabeth McPherson, Ridgefield, Washington; Ellen Nold, Stanford, California; Harvey Weiner, LaGuardia Community College of the City University of New York; and Richard L. Larson, Herbert H. Lehman College of the City University of New York, Coordinator.

These materials were completed and in type before the appearance of Davis, Scriven, and Thomas, The Evaluation of Composition Instruction (Inverness, CA: Edgepress, 1981). 
instruction in writing, we do not find them. There is simply no body of knowledge now available about the evaluation of instruction in writing, and the Committee finds no indication that research now under way might lead to such knowledge, except possibly in the three-year project at the University of Texas at Austin (directed by Stephen Witte and Lester Faigley), now at the end of its second year. None of the recent scholarly studies of effectiveness of instruction-for example, N. L. Gage's The Scientific Basis of the Art of Teaching, Albert Smith's Faculty Development and Evaluation in Higher Education, Richard Miller's Evaluating Faculty Performance, and John A. Centra's Determining Faculty Effectiveness-focus on the composition classroom at any level; few, in fact, focus to any substantial extent on the teaching of English. Much of the research on teaching effectiveness looks at teaching in the schools, and those studies that speak of college teaching, as the titles of Smith's, Miller's, and Centra's books suggest, typically focus on the total performance of faculty members, leaving aside the effectiveness of courses and programs-which should concern us just as much as the effectiveness of individual teachers. Even the work of Wilbert McKeachie and James Kulik of the University of Michigan, important contributors to the literature on evaluation of faculty and courses, does not directly address ways of evaluating teachers of writing, let alone courses and programs in writing.

Yet the Committee on Teaching and Its Evaluation in Composition is convinced that the teaching of writing has objectives different from those of most other kinds of teaching, and requires of teachers distinctive actions inside and outside the classroom. When we teach writing, we seek specifically to strengthen students' abilities to engage in a special, complex process-that of composing their thoughts and feelings into the symbols of language. We help students to perceive their worlds, to conduct inquiries, to analyze information, to synthesize perceptions and conceptions into original discourse-and thus, indeed, to learn about themselves and to influence their worlds by using language. Our focus as teachers of writing is on the process by which a writer prepares a text.

The Committee asserts, therefore, that the evaluation of instruction in writing requires special procedures and specially designed instruments that use distinctive questions-possibly adaptations of some of the procedures used to evaluate other kinds of teaching, but also new procedures not customarily used in evaluation of other teaching. Not only do we need to gather special data about instruction in writing, but also we need to develop distinctive criteria for use in making sense of those data.

What, then, are to be the special sources of data for evaluating instruction in writing? An answer that tempts some administrators is the measurement of 
progress and growth in students' writing; their assumption is that effective teaching produces measurable changes in the performance of those taught. These administrators would like to look at changes in scores on tests of writing-assigned by holistic or analytic readings of test papers-at changes in counts of specific features of diction and syntax in students' writing, or at changes in the composing processes followed by student writers before and after instruction.

Although the Committee recognizes that studying countable features of students' writing, and even comparing the composing processes of students (discovered from students' written accounts, or from tapes of their composing aloud) before and after instruction, can be useful in the evaluation of special instructional techniques, the Committee has seen no evidence that such comparisons lead to reliable evaluations of courses, programs, or teachers. Furthermore, these kinds of quantitative analyses must be conducted under rigorous methodological controls of the sort that may render them impractical for regular use. Often the writing used in the counting of stylistic features or the analyses of composing processes is obtained under test conditions so artificial that the value of the counts is quite limited. And many influences besides instruction affect the writing of the students tested. These procedures, which at first look like plausible steps toward evaluation, seem to the Committee, therefore, less than promising.

We have found, furthermore, no reason to suppose that looking at the grades awarded on course papers tells us much about the effectiveness of instruction. Paul Diederich has pointed out (in correspondence with the Committee) that the grades of students on essays-apart from being influenced by the luck of a student's assignment to a class-will tend over a period of time to "regress" toward the mean grade of the class, making inferences about students' gains or losses hard to draw. And the one study that attempted to gauge the durability of effects of instruction (using scores on multiple-choice tests as well as grades assigned on holistic readings of papers) showed no appreciable differences, after four semesters, between the work of students who had and those who had not received formal instruction in writing. But the study itself (conducted in the 1960's at the University of Northern Iowa) was described by reviewers writing in Research in the Teaching of English (in the Spring of 1970) as so seriously flawed in design that none of its findings "ought to be trusted whatsoever" (p. 70).

We have at this time, then, no basis for believing that testing students' writing or describing changes in their writing will permit useful judgments about the effectiveness of their instruction. All of the recent advances in techniques for holistic scoring of papers and all of the skill we are acquiring in developing and validating discrete-item tests-even though the results of those tests may correlate highly with grades assigned to students' papers by trained readers scoring holistically-appear of limited value when we seek to determine the overall effectiveness of writing programs, courses, and teachers. 
To what sources, then, can we turn for data that will help us in our professional work of evaluation? The Committee proposes that we first analyze the processes that teachers go through in planning and conducting a course or a program in writing-much as we are coming now to examine the processes that writers follow when they write. In discussing the process, we assume that as their first step teachers have accepted some theoretical framework for viewing the act of writing and the teaching of writing, and that within this framework they have defined the goals of their teaching. We further assume that as part of this step teachers have assessed where the students are when they begin the study of writing. Teachers then plan the sequence of activities in which the students will engage, and conduct those activities. The process ends only when teachers award final grades to the students.

For convenience in discussing evaluation, the Committee divides the process of teaching and learning in composition into seven parts: (1) the preliminary reflection and analysis just mentioned; (2) the planning of the curriculum and individual writing activities; (3) the successive classroom activities engaged in by teacher and student; (4) the instructional activitiesnot only writing and response to writing-in which instructor and students engage together outside the classroom; (5) the learning activities-especially writing-in which students engage by themselves during the course; (6) the performances-especially of writing-in which the students engage after instruction; (7) students' recollections of and feelings about their experiences. Obviously the sequential listing of these parts is misleading; the processlike that of writing-is recursive. Parts of the process repeat themselves, with variations, as instruction progresses; sub-processes (e.g., planning and modifying assignments) recur within larger parts of the process.

We all need to exercise some caution, of course, in gathering data about events in this process and in identifying criteria by which to view the data. First, we have to be aware at all times what values underlie our selection of criteria for interpreting data. Evaluators have to be aware, that is, of their own value systems for thinking about composition. The evaluator (to cite an obvious example) committed to the view that students of writing must learn English grammar might view data showing a large amount of students' class time spent on workbook drills quite differently from an evaluator who believes that effective writing depends on the students' acquiring distinctive voices. Second, we need to recognize that the very procedures and instruments of evaluation may imply to teachers and students who use these instruments a preference for one particular approach to teaching. (For instance, asking the students to say how much class time the teacher allowed them for revision of their papers may be thought to imply that allowing class time for revision is an important procedure.) As we construct an evaluation system, we must be sure that we gather adequate data to permit judgments and decisions about curricula, techniques, and teachers, and we must be equally sure 
that the processes of gathering data do not point toward one kind of judgment rather than another.

Working from this model of the process of teaching composition, the Committee offers the following six instruments and procedures, related to the successive parts of the process. The Committee is convinced that none of these instruments, used alone, will provide dependable insights into the effectiveness of a program, a course, or a teacher. In this conviction, the Committee finds support in the views of Albert B. Smith, in his monograph on Faculty Development and Evaluation in Higher Education; Smith believes that it is wise to have more than one "source of information" in program and faculty evaluation. We also find support in the work of Brenda Engel, who, in compiling her Handbook of Documentation (for use in evaluating instruction in the schools) for the North Dakota Study Group on Evaluation, enumerates a variety of materials that one can gather from students, teachers, and observers to help with evaluation. We believe that only by bringing together the information furnished by three or four of our instruments-some of them scorable numerically, some requiring qualitative interpretation-can a teacher or faculty determine in what ways a program, course, or teacher is more effective and in what ways less effective. In these instruments, of course, the Committee is expressing its convictions about what is to be valued in the teaching of writing; it believes that these values are consistent with the findings of modern scholarship in the teaching of writing.

The first of the Committee's six instruments asks that departments and administrators determine the assumptions, goals, and standards for judging writing that underlie the program or course, and that evaluators of instruction be familiar with all of these. These matters are themselves open to an evaluation of their internal consistency, and of their reasonableness given the institution's overall goals and the needs of students. Administrators and teachers must discuss together these assumptions and goals. Once the assumptions and goals are agreed upon, the other instruments can furnish data that will help to show how well the course or program serves its goals.

The Committee's second instrument enables teachers to describe and to evaluate their own courses. Self-evaluation can be a way of raising one's consciousness-a way of helping one meet the professional responsibility of knowing oneself and one's work. Instructors might keep a diary or a journal of their teaching, in which they record notes on classes, assignments, and other activities. These notes will help them complete the self-evaluation form at the end of the semester or the year. Teachers can compare the judgments they have made about their work with those of others, as recorded with the other four instruments here. The self-evaluation form also promotes discussion of the planning that undergirds assignments, classroom activities, and responses to students' papers. Such planning, as we have pointed out, precedes actual instruction; information about it is essential for interpretation of results gathered from the remaining four instruments.

The Committee next offers an instrument for guiding the direct observa- 
tion of classes in writing. The Committee knows the arguments against direct observation of classes. It has listened to the contention that one can rarely, if ever, tell how good a teacher is just by watching him or her teach. It recognizes that the presence of an observer can change the chemistry in the classroom-not to mention the behavior of students and teacher. But the Committee recognizes that many administrators of writing programs must observe the classes of their colleagues, and that departmental and college administrators often observe classes. And the Committee believes that if an observer watches a class after considering specifically how to look at a class in writing, the observer may be able to help teachers identify and correct problems with their teaching. Accordingly, the Committee offers a list of questions designed specifically for the writing classroom, and urges that those who observe classes make their analyses of the class sessions by applying these questions-and not by using the standard rating forms allegedly applicable to observation of any class.

The Committee's fourth instrument is a series of questions that can be asked of the assignments (or invitations) for writing. When the student writes, of course, the student learns, and the writing assignments are, therefore, the heart of the course or program. Yet they are seldom examined, or examined more than casually, in the process of evaluating instruction in writing. The Committee believes that they should be examined closely, because they reveal the teacher's understanding of the tasks that the student must perform in doing the assignment, the teacher's understanding of how people learn to write, the teacher's values about writing, and the teacher's ability to communicate with students in writing. Moreover, memoranda of writing assignments are durable (what takes place in a class or conference is fleeting) and can be examined at length; and the successive memoranda of assignments, in effect, disclose the essential structure of the course just as surely as the syllabus or the teacher's statement of purpose. The Committee recommends, therefore, the careful application of its eight questions to the teacher's writing assignments.

The Committee's fifth instrument is a set of suggestions for evaluating a teacher's responses to students' writing. This part of a teacher's work, also, is seldom examined in the evaluation of instruction in writing, but it is comparable in importance to the writing assignments. In their comments, teachers do a good deal of their teaching, not only giving advice but also imparting their criteria for judging writing and their values about writing. Furthermore, comments on students' writing (unless made orally in interviews, in which case they are inaccessible unless tape-recorded), like assignments, are durable; they need not be subject to selective, impressionistic recall. And, like assignments, teachers' comments should not be evaluated cursorily. Hence the Committee recommends careful application of its ten questions.

Finally, the Committee offers a set of suggested questions from which a teacher or administrator can draw in preparing a form for student rating of a 
writing program, course, and teacher. The use of student ratings of instruction, the Committee knows, has become widespread; many departments and some entire colleges gather student ratings of faculty, sometimes in compliance with directives from trustees. The use of such ratings has gathered a good deal of professional support, notably from Kenneth Eble (formerly head of the Carnegie Foundation-AAUP Project to Improve College Teaching), whose monograph, The Recognition and Advancement of Teaching, and whose talks at conferences argue strongly for the use of student ratings of instruction. Eble's position is supported by researchers in educational evaluation, who contend that, while students sometimes bring preferences and biases to questionnaires about instruction, their ratings can furnish useful information about a teacher's work. But the Committee has not seen any widely used rating forms, or any compilations of items for use on such forms (including the compilations prepared for use at the University of Massachusetts and Purdue University), that are largely directed, or even contain a few items identifiably directed, at programs in writing or teachers of writing. Nor has the Committee seen research arguing that the data gathered on the widely-used forms gives information that is helpful in assessing instruction in writing. The Committee believes that evaluation of such instruction must consider students' views of their experiences, but believes that the questions asked of students ought specifically to relate to instruction in writing.

The instruments that follow, obviously, do not reach every activity in a writing course. They do not look, for example, at what happens in conferences or at how texts are selected and used. Nonetheless, the Committee believes that these instruments give the basis of a much better plan for the evaluation of instruction in writing than materials now in use. It believes that those who teach writing and those who evaluate it should insist that evaluation be based on the freshest knowledge we have of the processes by which people write, learn to write, and teach writing. It offers these instruments and procedures as a positive alternative to the often incomplete, even inept, evaluation of instruction in writing currently practiced. It urges teachers and administrators who will use these materials to remember that the data they furnish about the processes and effects of teaching have to be interpreted in light of the users' assumptions, objectives, and perceptions of students. But the Committee is confident that use of these instruments may lead to new knowledge about writing and the teaching of writing-knowledge that may bring about development of new approaches to the training of teachers of writing and to the design of curricula for writing.

We would add that the Committee has prepared this statement and these materials primarily for use in college writing programs. But we think that they are equally applicable to writing programs and writing instruction in secondary schools, and we encourage teachers and administrators in secondary schools to reflect upon our findings and to use these materials in assessing the effectiveness of their programs and courses. 
The Committee wants very much to determine the usefulness and effectiveness of the materials presented here. Accordingly, we invite those who use some or all of these materials to write to us (in care of the Editor of this journal) about their experiences with the materials. If you do use any of these documents, we strongly encourage you to distribute them at the start of the year or semester when you will use them, so that people whose work they will help you to assess can get to know these documents. Some of the questions on which those who do use these materials may want to comment are the following (though we welcome comments on any aspect of the materials, not just on these questions):

1. Which documents from the group offered here did you use? In what ways did they work well? In what ways did they not work well? Which documents were helpful to you? Which less helpful? Why?

2. Are there items or questions that are inapplicable or not useful? Are specific items or materials missing?

3. How useful did these documents prove to be, in comparison to whatever procedures or documents you used previously?

4. How acceptable were the documents you used to those whose teaching you were evaluating?

5. What was your primary purpose in using the documents you did? What did the people whose teaching and whose courses you were evaluating think the purpose was?

6. If you used modified versions of these documents, what revisions did you make and why? What special characteristics of your students or your institution, if any, led to your revisions? Can you send us copies of the instruments as you used them?

We will appreciate, and will acknowledge, all comments and reports about the use of these documents.

\section{Information About Foundations of the Program}

In order to evaluate successfully a writing course, the evaluator must consider:

1. The teacher's or faculty member's values in writing and assumptions about what it means to "teach composition."

2. The students' background and preparation.

3. The goals of program.

4. The goals of the individual teacher. 
5. The teacher's stated criteria for awarding grades for individual papers or for the course or both.

6. The writing assignments.*

7. The teacher's reasons for ordering the assignments as he/she did.*

\title{
Questionnaire for Teachers
}

The questions and items in this section are not designed to be summarized in a score or on a graph. The questions are intended mainly to help teachers bring to consciousness features of their own techniques as instructors in composition, and to help them articulate their assumptions, goals, and plans in teaching writing. By developing this awareness, teachers will be able to compare their own perceptions of their work with those of otherscolleagues, students, perhaps administrators-who furnish information on the instruments in this package, and will be able to understand better the reasons for the success of their work as well as the areas in which they might strengthen their work.

\section{Part I}

1. What are the successive writing assignments in your class?

2. Why did you present the assignments in that order?

3. What changes would you make in these assignments if you taught the course again?

\section{Part II}

Please indicate the importance you attached to each of the following. In this course, I tried to teach my students how to-

$\begin{array}{ccccc}\text { Major/ } & \text { Somewhat } & \text { Not Very } & \text { At All } & \text { Not } \\ \text { Important } & \text { Important } & \text { Important } & \text { Important } & \text { Relevant }\end{array}$

1. define an issue to write about

$$
1
$$

$$
2
$$

3

4

2. come up with ideas for use in writing

3. state a main idea

1

1

4. support main ideas

2
2

3

3

5. use appropriate details

1

1

1
3

3

4

\author{
.
}




\section{Not \\ Major/ Somewhat Not Very At All Not Important Important Important Important Relevant}

6. locate sources of details

7. organize papers 12

8. recognize different tones in writing

2

3
3

4

5

2

4

5

9. select appropriate words

1

2

3

5

10. plan papers before writing

11. revise papers

12 . revise the organization of papers

13. revise sentences

14. revise ideas

1

2

4

15. correct their own mistakes in punctuation and grammar

1

3

4

5

12

5

1

2

4

5

12

2

1

2

5

$\begin{array}{lll}3 & 4 & 5 \\ 3 & 4 & 5\end{array}$

3

5

16. use a dictionary when needed

17. adjust their writing styles according to the purpose of their writing

1

2

34

5

1

3

5

18. adjust their writing styles according to the needs of their readers

19. learn new words

20. take essay tests

21. judge their own writing

22. judge other student's writing

23. ask questions about problems they face in their writing

24. use other people's comments to help them improve their writing

25 . extend the principles learned in this class to writing in other classes 
Part III

Indicate how frequently your class engaged in-

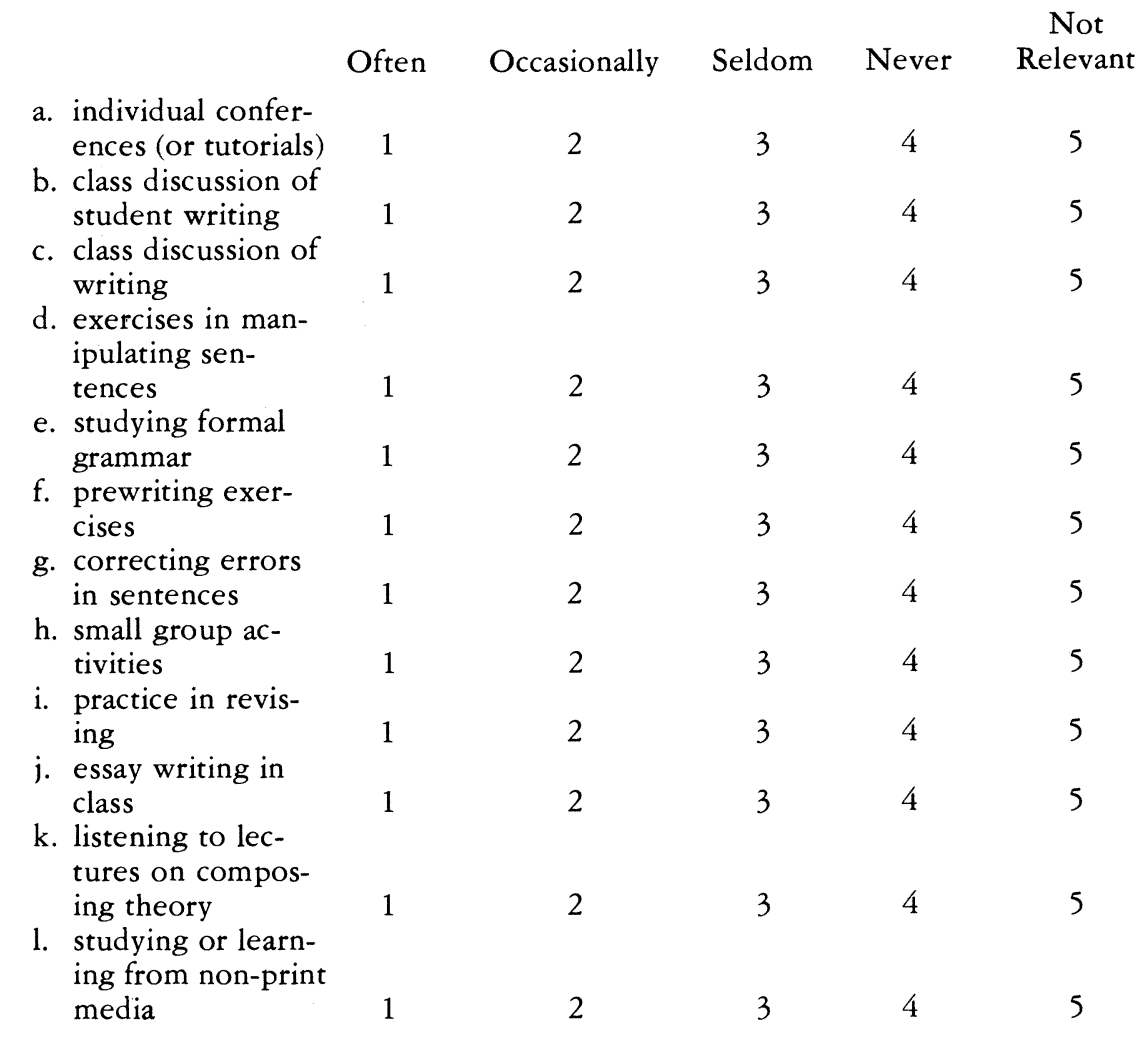

Part IV

1. What were the most successful features of this course?

2. What would you change about the course if you taught it again?

3. How did you explain your grading standards to your students?

\section{Evaluating Classroom Activities Through Observation by Colleagues}

The person who evaluates classroom performance must keep in mind that the presence of an observer creates an element of artificiality within the class, and must be alert to possible effects of his or her presence on what happens in the class. The observer should be aware, also, of any special circumstances (e.g., proximity to examination periods, other potential stresses on students or teacher) within which the class is taught. In planning for the observation, 
the observer should find out how the particular session fits into the plan for the course: the syllabus (explicit or implicit), the sequence of writing assignments, other instructional activities, and the responses students are receiving to their work. The observer should learn the goals of the class and should learn what the teacher intends to have take place. And the observer should plan to share with the teacher the observer's perception of what went on in the classroom, including distinctive strong points and points on which the teacher will want to strengthen his or her work.

With this advice in mind, the observer should consider these questions:

1. Is the focus or goal of the class clear?

2. Is the focus or goal, as it emerges during the class, congruent with the teacher's assumptions, objectives, and plans as identified in preliminary conversations with the teacher (and in the reflections carried on under Document 1)?

3. Is the classroom activity directly related, in a clear way, to instruction in writing?

4. Does the discussion in class focus directly either on the processes of writing or on ways of using language effectively in writing or on ways in which readers might respond to writing (and thus on ways of determining the effectiveness of a piece of writing)?

5. Does the teacher engage the students in learning activities related to the goals for the day's class?

6. Are the teaching techniques and classroom activities appropriate to the preparation and background of the students?

7. Do students seem personally involved in the activities of the class?

8. Does what is taught make sense as advice to writers about writing?

9. Does the teacher's behavior indicate that he or she thinks that the students can learn to improve their writing?

10. Is the teacher audible to everyone?

11. Can the students understand the teacher's language?

12. Does the teacher encourage students' questions?

13. Does the teacher respond to questions and comments in a positive, constructive way?

\section{Some Questions to Ask When Judging Assignments for Writing}

1. By what means and with what accompanying explanations or models has the assignment been given to students?

2. Has the assignment been clearly stated?

3. Do the students know for sure what they are expected to do? Is there opportunity for questions? 
4. Does the assignment guide the student in selecting materials, identifying pertinent questions and issues, and choosing perspectives on a subject? If the student is not so guided, is there a reason why?

5. Does the assignment reflect one or more of the goals of the course?

6. If the assignment is for writing in class, can most students complete it in the time allotted?

7. Is the student invited to define his or her role and audience?

8. Is the assignment appropriate for students at this level?

\section{Guidelines for Evaluation of Teacher's Commentaries on Student Papers}

1. Do comments or questions address the stated goals of the assignment?

2. Do the comments take into account the writer's goals for writing?

3. Are the comments themselves models of clear prose?

4. Are there some comments that address strengths in the paper?

5. Do the comments identify objectively what the students have and have not done?

6. Do the comments suggest ways to improve the writing either for a revision or a later assignment?

7. Do the comments have a constructive tone?

8. Is the number of comments such that the student can assimilate them?

9. Do the comments explain the instructor's judgments on the writing?

10. Do the comments make suggestions that are appropriate for the student's level of ability?

11. Are the comments specific enough so that the student can tell how they apply to his/her paper?

\section{Obtaining Students' Judgments on Their Instruction}

The following pages offer a large collection of items for possible use on student rating instruments for courses (or programs) in writing. More items are listed than any teacher or faculty would probably want to use; some items repeat the thrust of other items in different language. The items are arranged in three large groups; two other groups ask for semifactual information, and permit students to comment freely upon the course.

The Committee suggests that teachers and/or faculties in writing make up their own rating instrument for writing courses by drawing from this list the items that reflect their objectives, conceptual framework, and perceptions of 
students' needs and abilities. Some teachers will want more items, some will want fewer. Some may wish to add items of their own that address distinctive philosophies or techniques for teaching.

Each item in the list invites a response in categories such as "Agree," "Disagree," "Not relevant." Some users may want to allow five responses, some may prefer four. Instructions will ask students to circle the appropriate response (as they see it), and may tell students that their answers can help the department make changes in the way a course is planned and/or help teachers make changes in the way the course is taught. The questionnaire is designed for anonymity, and students should be assured that they will not in any way be identified.

\section{Part I}

I was absent approximately times.

I was late for class approximately times.

I did writing assignments.

The grade I expect in this course is

I met with my instructor outside of class times.

I visited the writing center number of times.

\section{Part II}

The course helped me improve my ability-

1. to define an issue to write about.

Very Much Somewhat

A Little $\begin{gathered}\text { Not At } \\ \text { All }\end{gathered} \quad \begin{gathered}\text { Not } \\ \text { Relevant }\end{gathered}$

2. to come up with ideas for use in writing

1

2

3

4

5

3. to state a main idea

1

2

3

4

4. to support my main ideas

1

2

3

4

5. to use appropriate details

1

2

3

4

6. to locate sources of details

1

3

4

7. to organize my papers

1

8. to use appropri-

1




\section{Very Much Somewhat A Little $\begin{array}{ccc}\text { Not At } & \begin{array}{c}\text { Not } \\ \text { Relevant }\end{array}\end{array}$}

9. to choose words that say what I mean

$$
1
$$$$
2
$$

10. to plan papers before I write

11. to revise my papers

12. to revise the organization of my papers

1

$$
2
$$

. to revise my sentences

1

2

3

to revise my ideas

15. to correct my own mistakes in punctuation and grammar

16. to use a dictionary when needed

17. to adjust my writing style according to the purpose of my writing

1

18. to adjust my writing style according to the needs of my readers

19. to learn new words

20. to take essay tests

21. to judge my own writing

22. to judge other student's writing

23. to state for myself questions about my problems in writing

24. to use other people's comments to improve my writing

25. to write in other courses 
Part III

After taking this class, I believe that-

Strongly

Agree

1. I am better able to do my writing assignments

2. I am more willing to undertake writing tasks

3. I have increased confidence in myself as a writer

4. I am more willing to take jobs that may require writing

5. I am more willing to take courses that may require writing

6. writing can help me learn

7. writing helps me to clarify my ideas

8. the teacher's evaluation of my writing seemed fair

9. my writing was treated with respect

10. my teacher was regularly prepared for class
1

1

1

1

1

1

1

1

1

1

1

\section{Strongly Not \\ Agree Disagree \\ Disagree \\ Relevant}

2

2

2

2

3

4

5

5

5

5

5

5

34

45

Part IV

In this course I was able to-

Always Often Occasionally Never $\begin{gathered}\text { Not } \\ \text { Relevant }\end{gathered}$

1. understand what the teacher was talking about

1

2

3

4

2. ask questions whenever I

wanted to

1

2

3

4 
Always Often Occasionally Never $\begin{gathered}\text { Not } \\ \text { Relevant }\end{gathered}$

3. disagree with the teacher if I wanted to

4. join freely in class discussions

5. understand the purpose of the writing assignments

6. understand how the assignments related to one another

practice writing for other audiences

1

2

3

5

1

2

3

5

8. share my writing with others in the class

use my teacher's comments to improve my writing

1

1

2

3

5

12

3

5

12

3

4

5

10. understand my teacher's comments about my writing 1

2

3

4

11. understand my teacher's

standards for grading

1

2

3

4

5

12. get responses to my writing assignments in a reasonable length of time

13. confer with my teacher outside of class

5

5

5

